\title{
Review Article \\ Vascular Calcification in Chronic Kidney Disease: The Role of Inflammation
}

\author{
Kerstin Benz, ${ }^{1}$ Karl-Friedrich Hilgers, ${ }^{2}$ Christoph Daniel $\left(\mathbb{D},{ }^{1}\right.$ and Kerstin Amann $\mathbb{D}^{1}$ \\ ${ }^{1}$ Department of Nephropathology, Friedrich-Alexander University (FAU) Erlangen-Nürnberg, Germany \\ ${ }^{2}$ Department of Nephrology and Hypertension, Friedrich-Alexander University (FAU) Erlangen-Nürnberg, Germany
}

Correspondence should be addressed to Kerstin Amann; kerstin.amann@uk-erlangen.de

Received 18 April 2018; Accepted 24 July 2018; Published 13 August 2018

Academic Editor: Nicolas Verheyen

Copyright (C) 2018 Kerstin Benz et al. This is an open access article distributed under the Creative Commons Attribution License, which permits unrestricted use, distribution, and reproduction in any medium, provided the original work is properly cited.

Cardiovascular complications are extremely frequent in patients with chronic kidney disease (CKD) and death from cardiac causes is the most common cause of death in this particular population. Cardiovascular disease is approximately 3 times more frequent in patients with CKD than in other known cardiovascular risk groups and cardiovascular mortality is approximately 10 fold more frequent in patients on dialysis compared to the age- and sex-matched segments of the nonrenal population. Among other structural and functional factors advanced calcification of atherosclerotic plaques as well as of the arterial and venous media has been described as potentially relevant for this high cardiovascular morbidity and mortality. One potential explanation for this exceedingly high vascular calcification in animal models as well as in patients with CKD increased systemic and most importantly local (micro)inflammation that has been shown to favor the development of calcifying particles by multiple ways. Of note, local vascular upregulation of proinflammatory and proosteogenic molecules is already present at early stages of CKD and may thus be operative for vascular calcification. In addition, increased expression of costimulatory molecules and mast cells has also been documented in patients with CKD pointing to a more inflammatory and potentially less stable phenotype of coronary atherosclerotic plaques in CKD.

\section{Introduction}

Patients with chronic kidney disease (CKD) and chronic renal failure (CRF) develop early on in the course of the disease structural and functional alterations of the heart and the vascular tree that represent a major clinical problem in these patients. In addition, cardiovascular diseases are a major contributor to the high incidence of cardiovascular complications and particularly death from cardiovascular causes in this population $[1,2]$. Apart from left ventricular hypertrophy $(\mathrm{LVH})$ which is present very early in the course of the renal disease even in normotensive CKD patients structural alterations of the myocardium as well as the intra- and extracardiac arteries and veins are hallmarks of this disease. With respect to the myocardium reduced myocardial capillary supply, interstitial fibrosis and thickening of the intramyocardial arteries can be seen [3-5]. These intramyocardial structural alterations increase the susceptibility of the hypertrophied heart of CKD patients towards ischemic damage and favor the development of arrhythmias, myocardial infarction, and sudden cardiac death [6]. The pathogenesis of these myocardial alterations is certainly multifactorial, but only partly understood. Among the mechanisms that have been described for LVH and the associated myocardial alterations are the so-called classical or traditional risk factors like hypertension, hyperlipidemia, and diabetes but also CKDspecific changes such as anemia, hypervolemia, increased sympathetic activity, hyperphosphatemia, oxidative stress, and altered expression of the fibroblast growth factor 23 (FGF-32) $[7,8]$. As a consequence clinical strategies to prevent or ameliorate $\mathrm{LVH}$ and associated structural alterations in CKD comprise prevention of anemia by normalization of the hemoglobin value $(\mathrm{Hb})$, prevention of hypervolemia, and strict blood pressure control particularly with ACEinhibitors. In experimental models of chronic renal failure blockade of the renin-angiotensin system (RAS), the endothelin (ET) system, pharmacological and mechanical 


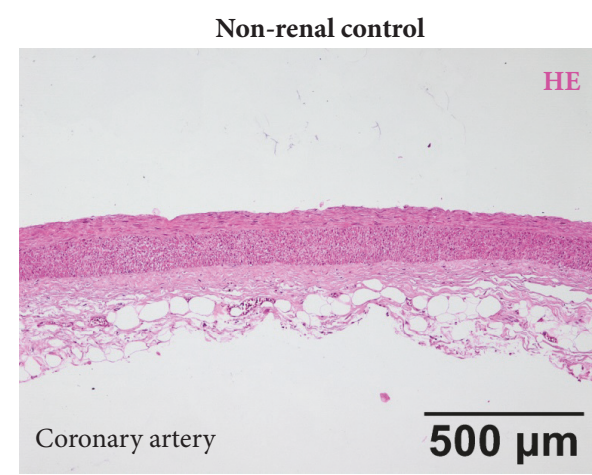

(a)

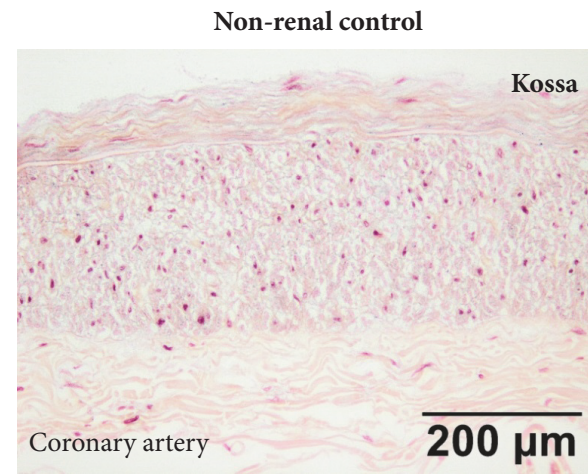

(c)

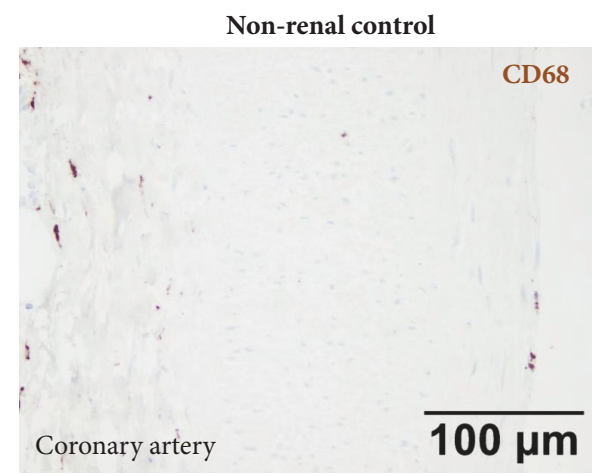

(e)

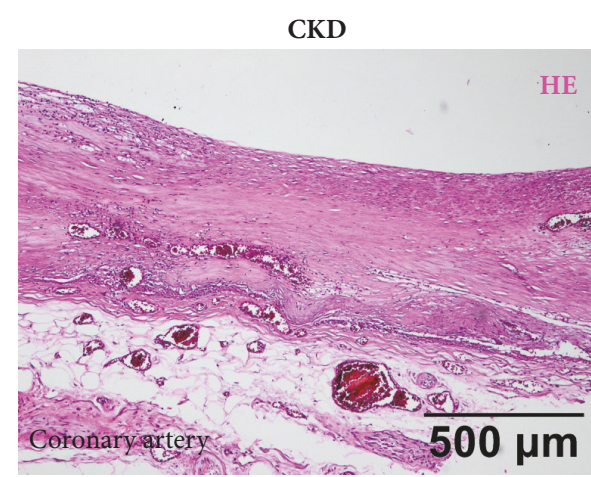

(b)

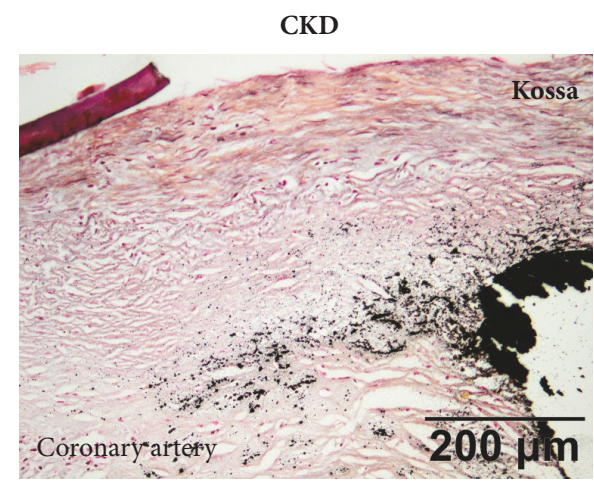

(d)

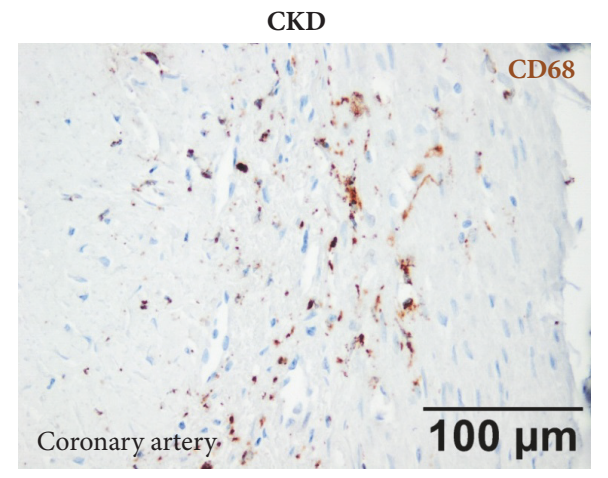

(f)

FIGURE 1: (a-f) Representative vascular findings in nonrenal control patients (a, c, e) and patients with chronic kidney disease (CKD). (a, b) Marked thickening of coronary arteries in CKD patients (b) compared to nonrenal controls (a). HE-stain. (c, d) Marked calcification of the arterial intima and media and atherosclerotic coronary plaques in CKD patients (d) compared to nonrenal controls (d). Von Kossa stain. (e, f) Increased number of CD68 positive macrophages in the vascular wall of CKD patients (f) compared to nonrenal controls (e). Immunohistochemistry.

inhibition of the sympathetic nervous system, and blockade of the FGF23-axis [9-13] were also shown to be successful.

In addition to the cardiac alterations specific structural changes of the extracardiac arteries and veins are present which consist of vessel thickening (Figures 1(a) and 1(b)) but more importantly of marked calcification of the arterial intima and media as well as of venous walls and atherosclerotic coronary plaques giving rise to complications such as coronary artery thrombosis and myocardial infarction [1418]. Based on their clinical experience the group of Lindner and coworkers in 1974 [19] were the first to show that atherosclerosis in CKD patients is different from that of nonrenal patients. They particularly showed that the lesions were more advanced and the course of atherosclerosis in these patients was more aggressive. Consequently, they speculated that this may contribute to the exceedingly high cardiovascular morbidity and mortality in these patients. The functional consequences of increase vascular and plaques calcification are manifold: it leads to increased stiffness of the vessel which in the case of the arterial tree increases the cardiac afterload and impairs coronary artery perfusion [20-22]. In an autoptic study Schwarz and coworkers $[23,24]$ were able 
to confirm that indeed the coronary atherosclerotic lesions in CKD patients were more advanced than in nonrenal control patients and perhaps more importantly that particularly the calcified plaque lesions were significantly more present in CKD patients (Figures 1(c) and 1(d)). This and other findings prompted in vitro and in vivo studies investigating the underlying pathogenesis of increased plaque and vessel calcification in CKD.

\section{Potential Pathogenesis of Advanced Vascular Calcification in CKD}

Although the exact pathogenesis of increased vascular calcification in CKD is not fully understood there are some very plausible hypotheses and candidates: from the very beginning disturbances in the phosphorus $(\mathrm{P})$ and calcium (Ca) metabolism $[25,26]$, altered expression of many factors, which are involved or regulate the mineral metabolism [27, 28], and perhaps most importantly chronic microinflammation which is present in CKD patients early on in the disease and comes along with increased CRP levels [29, 30] have been discussed as important pathogenetic factors. Particularly, early on a major pathogenetic role of $\mathrm{P}$ and $\mathrm{Ca}$ has emerged from clinical $[31,32]$ and experimental studies $[33,34]$ where a strong correlation between serum values of both $\mathrm{P}$ and $\mathrm{Ca}$ and perhaps more importantly the Ca-P product (CaxP) and cardiovascular events could be shown [35]. On the other hand, experimental manipulation with high and low phosphate diet in an animal model of chronic renal failure, i.e., the subtotally nephrectomized rat (SNX), could clearly document the deleterious cardiovascular effect of high phosphate [34]. It has also been shown in vitro that increased $\mathrm{P}$ and Ca levels can induce osteoblast-like changes in vascular smooth muscle cells (VSMC) via stimulation of $\mathrm{Na}$-dependent $\mathrm{P}$-cotransporters $[36,37]$. This is reflected by de novo expression of specific marker proteins of osteogenic differentiation like cbfa-1 und osteocalcin which coincide with a change in phenotype of VSMC from a contractile to a secretory calcifying cell. In patients with CKD the expression of calcification-inhibiting proteins like Fetuin-A, MGP, betaGlucosidase, and osteoprotegerin is reduced which may also contribute to a procalcific milieu $[38,39]$. Very recently, serum calciprotein particles and circulating nanostructures, such as extracellular vesicles, have been identified as important players in the mechanism of calcification in CKD mainly by promoting cell osteochondrogenic differentiation and inflammation [40]. Vice versa, a role for inhibition of mineral crystal formation by Gla-rich protein which in vitro could prevent calciprotein particles induced calcification was postulated.

\section{Role of Systemic and Local Inflammation in Vascular Calcification}

The above-mentioned recent study by Viegas and coworkers [40] more emphasizes a potential role of inflammation for vascular calcification in CKD. Systemic and local effects of inflammation on vascular alterations in CKD but also in other segments of the general population are being discussed for quite some time [41, 42]. In addition, to the many excellent data on increased systemic inflammation in CKD that can be monitored by elevated inflammatory biomarkers such as CRP [30] and IL-6 [43-45] there is also experimental evidence for a major role of local inflammation in the pathogenesis of advanced atherosclerosis in renal failure [24]. In CKD patients our group could show that coronary artery plaques are not only more advanced than in nonrenal control patients but also exhibit a more inflammatory phenotype with increased local expression of proinflammatory systems such as the CD40-CD154 ligand system and also macrophages (Figures 1(e) and 1(f)) which has been associated with increased risk of atherosclerotic events [46]. In addition, we could recently show [47] that local upregulation of proinflammatory and proosteogenic molecules such as CRP, CD40, CD154, and SATB2 as well as galectin-3 is already present at early stages of CKD in various vessels (Figure 2), i.e., the A. mammaria int., the V. saphena magna, and the aorta taken at the occasion of cardiac surgery [47]. Of note, local microinflammation was even seen in the absence of major disturbances of the CaxP product and could thus be most likely regarded independent of changes in $\mathrm{P}$ or $\mathrm{Ca}$. Local microinflammation also preceded the development of vascular calcification, a finding that may point to an early and important pathophysiological role of (pro)inflammatory changes. In addition, we recently investigated a potential role for dendritic cells (DCs) and particularly mast cells (MCs) in the pathogenesis of coronary atherosclerosis in CKD [48]. These cells might be important since a role of DCs and MCs for inflammation, immunity, and T-cell-activation in atherosclerosis [49-55] has been shown. Consequently, DCs and MCs may represent novel therapeutic targets [56] for treatment of atherosclerosis and its complications. Of note, patients with CKD are known to show clinical and laboratory features of immunosuppression with low numbers of T-cells and circulating DCs as well as impaired T-cell activation [57-59], most likely as a consequence of suppressive effects of CKD on the bone marrow and cell maturation. Using immunohistochemistry, Hueso et al. [60] investigated aortic lesions of CKD and control patients, i.e., adaptive as well as pathological intimal thickening of the aorta and fibroatheromas and found a significantly higher percentage of DCs in CKD patients compared to non-CKD controls. In contrast, in coronary arteries we found a lower number of DCs in CKD compared to nonrenal control patients. DCs were predominantly located in the shoulder, boundary, and basis subregions of plaques in good correlation with the Stary classification of atherosclerotic lesions. In addition, in the shoulder and cap region DCs positivity correlated with Tcells and macrophages potentially indicating a proinflammatory role of DCs that might be important in terms of plaque instability. It is also speculated that DCs activation by nicotine, stress, hypoxia, or CRP may stimulate the local immune response [61]. This might be of interest in view of our previous finding of an increased in situ expression of CRP in atherosclerotic plaques of CKD patients compared to controls [46]. With respect to the effect of CKD on MC number and distribution we found a tendency for more 


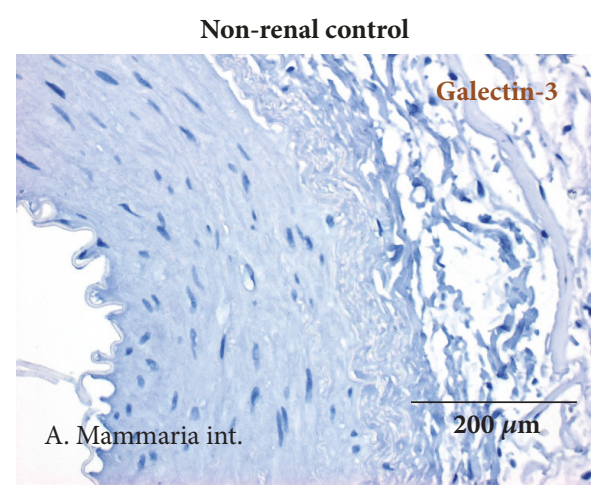

(a)

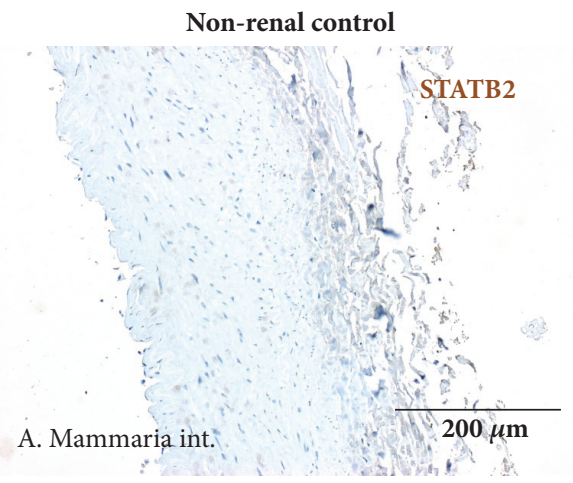

(c)

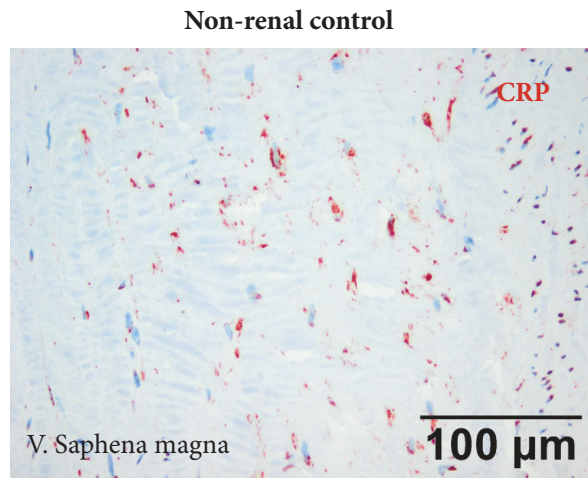

(e)

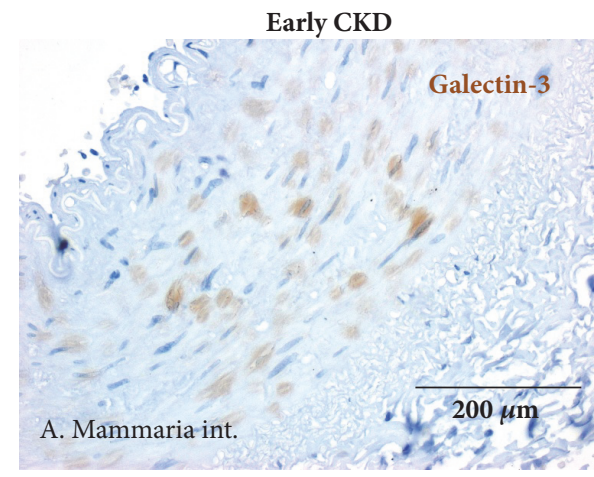

(b)

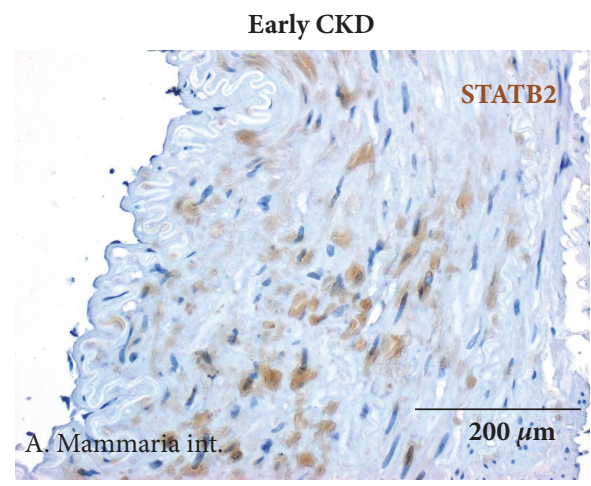

(d)

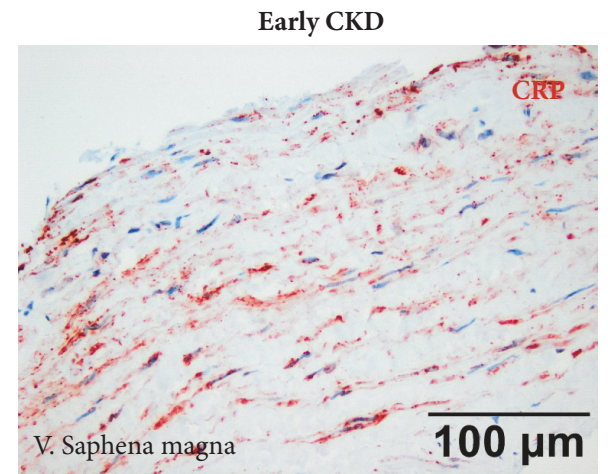

(f)

FIGURE 2: (a-f) Representative vascular changes in nonrenal control patients (a, c, e) and patients with early chronic kidney disease (CKD). ( $a, b)$ Increased expression of galectin-3 in arteria mammaria int. in early CKD patients (b) compared to nonrenal controls (a). Immunohistochemistry. (c, d) Marked increase in STAB2 expression in arteria mammaria int. in early CKD patients (d) compared to nonrenal controls (d). Immunohistochemistry. (e, f) Increased staining for C-reactive protein (CRP) in vena saphena magna in early CKD patients (f) compared to nonrenal controls (e). Immunohistochemistry.

MCs in vessels from end-stage CKD patients particularly in calcified ones. This finding potentially points to a specific role of MCs compared to DCs under the condition of renal failure and particularly in vessel calcification. Detailed correlation analysis of MCs with inflammatory cells such as T-cells and macrophages inside plaques subregions revealed a positive association with T-cells in end-stage CKD specimens and a significant correlation between the MC score within the plaque and the serum C-reactive protein (CRP) levels, again suggesting a potential link of MCs to local intraplaque T-cell and macrophage activation and also to systemic inflammation.

\section{Summary and Conclusion}

Advanced stages of atherosclerotic plaques particularly with plaque and vessel calcification are specific features in patients with CKD that might contribute to the high cardiovascular morbidity and mortality in these patients. Our findings of a more inflammatory phenotype of coronary atherosclerotic 
plaques and particularly of a potential role of MCs for advanced atherosclerosis in CKD might be particularly important in view of recent experimental findings in the animal model of the ApoE knockout mouse [62] where pharmacological MC chymase inhibition using the protease inhibitor RO5066852 was shown to reduce atherosclerotic plaque progression and to improve plaque stability. If this novel experimental finding could be successfully translated into the human situation pharmacological MC inhibition might possibly evolve as a new therapeutic target in the treatment of atherosclerosis particularly in the advanced condition of chronic renal failure. In order to find adequate and effective treatment strategies it is tremendously important to gain further insight into the exact mechanisms of calcification under the conditions of CKD $[63,64]$. It is most likely that in the near future we aim at specific treatment options for hyperphosphatemia, chronic microinflammation, and increased FGF-23 levels and may be also MC chymase inhibition in patients with CKD that might help to lower the exceedingly high cardiovascular risk in this particular population group.

\section{Conflicts of Interest}

The authors declare that they have no conflicts of interest.

\section{Acknowledgments}

The authors acknowledge support by Deutsche Porschungsgemeinschaft and Friedrich-Alexander-Universität ErlangenNürnberg (FAU) within the funding programme Open Access Publishing.

\section{References}

[1] K. Amann, C. Wanner, and E. Ritz, "Cross-talk between the kidney and the cardiovascular system," Journal of the American Society of Nephrology, vol. 17, no. 8, pp. 2112-2119, 2006.

[2] C. Wanner, K. Amann, and T. Shoji, "The heart and vascular system in dialysis," The Lancet, vol. 388, no. 10041, pp. 276-284, 2016.

[3] K. Amann and E. Ritz, "Microvascular disease-the Cinderella of uraemic heart disease," Nephrology Dialysis Transplantation, vol. 15, no. 10, pp. 1493-1503, 2000.

[4] K. Amann, "Cardiovascular changes in chronic renal failurepathogenesis and therapy," Clinical Nephrology, vol. 58, 1, pp. S62-S72, 2002.

[5] K. Amann and E. Ritz, "The heart in renal failure: morphological changes of the myocardiom - new insights," Journal of Clinical and Basic Cardiology, vol. 4, pp. 109-113, 2001.

[6] R. Dikow, L. P. Kihm, M. Zeier et al., "Increased infarct size in uremic rats: Reduced ischemia tolerance?" Journal of the American Society of Nephrology, vol. 15, no. 6, pp. 1530-1536, 2004.

[7] J. Himmelfarb, P. Stenvinkel, T. A. Ikizler, and R. M. Hakim, "The elephant in uremia: oxidant stress as a unifying concept of cardiovascular disease in uremia," Kidney International, vol. 62, no. 5, pp. 1524-1538, 2002.
[8] C. Faul, A. P. Amaral, B. Oskouei et al., "FGF23 induces left ventricular hypertrophy," The Journal of Clinical Investigation, vol. 121, no. 11, pp. 4393-4408, 2011.

[9] K. Amann, P. Gassmann, M. Buzello et al., "Effects of ACE inhibition and bradykinin antagonism on cardiovascular changes in uremic rats," Kidney International, vol. 58, no. 1, pp. 153-161, 2000.

[10] K. Amann, J. Hofstetter, V. Câmpean et al., "Nonhypotensive dose of $\beta$-adrenergic blocker ameliorates capillary deficits in the hearts of rats with moderate renal failure," Virchows Archiv, vol. 449, no. 2, pp. 207-214, 2006.

[11] K. Amann, K. Münter, S. Wessels et al., "Endothelin a receptor blockade prevents capillary/myocyte mismatch in the heart of uremic animals," Journal of the American Society of Nephrology, vol. 11, no. 9, pp. 1702-1711, 2000.

[12] K. Amann, K. Tyralla, M.-L. Gross et al., "Cardiomyocyte loss in experimental renal failure: Prevention by ramipril," Kidney International, vol. 63, no. 5, pp. 1708-1713, 2003.

[13] G. S. Di Marco, S. Reuter, D. Kentrup et al., "Treatment of established left ventricular hypertrophy with fibroblast growth factor receptor blockade in an animal model of CKD," Nephrology Dialysis Transplantation, vol. 29, no. 11, pp. 2028-2035, 2014.

[14] V. Campean, D. Neureiter, I. Varga et al., "Atherosclerosis and vascular calcification in chronic renal failure," Kidney and Blood Pressure Research, vol. 28, no. 5-6, pp. 280-289, 2006.

[15] K. Amann, "Media calcification and intima calcification are distinct entities in chronic kidney disease," Clinical Journal of the American Society of Nephrology, vol. 3, no. 6, pp. 1599-1605, 2008.

[16] W. G. Goodman, "Vascular calcification in end-stage renal disease," Journal of Nephrology, vol. 15, no. 6, pp. S82-S85, 2002.

[17] W. G. Goodman, J. Goldin, B. D. Kuizon et al., "Coronary-artery calcification in young adults with end-stage renal disease who are undergoing dialysis," The New England Journal of Medicine, vol. 342 , no. 20 , pp. 1478-1483, 2000.

[18] M.-L. Gross, H.-P. Meyer, H. Ziebart et al., "Calcification of coronary intima and media: Immunohistochemistry, backscatter imaging, and x-ray analysis in renal and nonrenal patients," Clinical Journal of the American Society of Nephrology, vol. 2, no. 1, pp. 121-134, 2007.

[19] A. Lindner, B. Charra, D. J. Sherrard, and B. H. Scribner, "Accelerated atherosclerosis in prolonged maintenance hemodialysis," The New England Journal of Medicine, vol. 290, no. 13, pp. 697701, 1974.

[20] G. M. London, A. P. Guérin, S. J. Marchais, F. Métivier, B. Pannier, and H. Adda, "Arterial media calcification in end-stage renal disease: Impact on all-cause and cardiovascular mortality," Nephrology Dialysis Transplantation, vol. 18, no. 9, pp. 1731-1740, 2003.

[21] G. M. London, S. J. Marchais, and A. P. Guerin, "Arterial stiffness and function in end-stage renal disease," Advances in Chronic Kidney Disease, vol. 11, no. 2, pp. 202-209, 2004.

[22] K. Amann and E. Ritz, "Cardiovascular abnormalities in ageing and in uraemia - Only analogy or shared pathomechanisms?" Nephrology Dialysis Transplantation, vol. 13, no. 7, pp. 6-11, 1998.

[23] U. Schwarz, M. Buzello, E. Ritz et al., "Morphology of coronary atherosclerotic lesions in patients with end-stage renal failure," Nephrology Dialysis Transplantation, vol. 15, no. 2, pp. 218-223, 2000.

[24] S. B. Schwedler, K. Amann, K. Wernicke et al., "Native Creactive protein increases whereas modified $\mathrm{C}$-reactive protein 
reduces atherosclerosis in apolipoprotein E-knockout mice," Circulation, vol. 112, no. 7, pp. 1016-1023, 2005.

[25] W. G. Goodman, "Importance of hyperphosphataemia in the cardio-renal axis," Nephrology Dialysis Transplantation, vol. 19, no. 1, pp. i4-i8, 2004.

[26] K. Amann, M.-L. Gross, G. M. London, and E. Ritz, "Hyperphosphataemia - A silent killer of patients with renal failure?" Nephrology Dialysis Transplantation, vol. 14, no. 9, pp. 20852087, 1999.

[27] M. Ketteler, C. Wanner, T. Metzger et al., "Deficiencies of calcium-regulatory proteins in dialysis patients: A novel concept of cardiovascular calcification in uremia," Kidney International Supplements, vol. 63, no. 84, pp. S84-S87, 2003.

[28] C. Schäfer, A. Heiss, A. Schwarz et al., "The serum protein $\alpha_{2}$-Heremans-Schmid glycoprotein/fetuin-A is a systemically acting inhibitor of ectopic calcification," The Journal of Clinical Investigation, vol. 112, no. 3, pp. 357-366, 2003.

[29] E. Ishimura, S. Okuno, K. Kitatani et al., "C-reactive protein is a significant predictor of vascular calcification of both aorta and hand arteries," Seminars in Nephrology, vol. 24, no. 5, pp. 408412, 2004.

[30] J. Zimmermann, S. Herrlinger, A. Pruy, T. Metzger, and C. Wanner, "Inflammation enhances cardiovascular risk and mortality in hemodialysis patients," Kidney International, vol. 55, no. 2, pp. 648-658, 1999.

[31] G. A. Block, "Prevalence and clinical consequences of elevated Ca x P product in hemodialysis patients," Clinical Nephrology, vol. 54, no. 4, pp. 318-324, 2000.

[32] G. A. Block, T. E. Hulbert-Shearon, N. W. Levin, and F. K. Port, "Association of serum phosphorus and calcium x phosphate product with mortality risk in chronic hemodialysis patients: a national study," American Journal of Kidney Diseases, vol. 31, no. 4, pp. 607-617, 1998.

[33] K. Amann, E. Ritz, G. Wiest, G. Klaus, and G. Mall, "A role of parathyroid hormone for the activation of cardiac fibroblasts in uremia," Journal of the American Society of Nephrology, vol. 4, no. 10, pp. 1814-1819, 1994.

[34] K. Amann, J. Törnig, B. Kugel et al., "Hyperphosphatemia aggravates cardiac fibrosis and microvascular disease in experimental uremia," Kidney International, vol. 63, no. 4, pp. 12961301, 2003.

[35] S. M. Moe, "Current issues in the management of secondary hyperparathyroidism and bone disease," Peritoneal Dialysis International, vol. 21, no. 3, pp. S241-S246, 2001.

[36] C. M. Giachelli, "Vascular calcification: in vitro evidence for the role of inorganic phosphate," Journal of the American Society of Nephrology, vol. 14, 4, no. 9, pp. S300-S304, 2003.

[37] N. X. Chen, K. D. O’Neill, D. Duan, and S. M. Moe, "Phosphorus and uremic serum up-regulate osteopontin expression in vascular smooth muscle cells," Kidney International, vol. 62, no. 5, pp. 1724-1731, 2002.

[38] S. M. Moe, D. Duan, B. P. Doehle, K. D. O'Neill, and N. X. Chen, "Uremia induces the osteoblast differentiation factor Cbfal in human blood vessels," Kidney International, vol. 63, no. 3, pp. 1003-1011, 2003.

[39] S. M. Moe, K. D. O’Neill, D. Duan et al., "Medial artery calcification in ESRD patients is associated with deposition of bone matrix proteins," Kidney International, vol. 61, no. 2, pp. 638-647, 2002.

[40] C. S. Viegas, L. Santos, A. L. Macedo et al., "Chronic Kidney Disease Circulating Calciprotein Particles and Extracellular
Vesicles Promote Vascular Calcification: A Role for GRP (GlaRich Protein)," Arteriosclerosis, Thrombosis, and Vascular Biology, vol. 38, no. 3, pp. 575-587, 2018.

[41] A. Mehta, J. Patel, M. Al Rifai et al., "Inflammation and coronary artery calcification in South Asians: The Mediators of Atherosclerosis in South Asians Living in America (MASALA) study," Atherosclerosis, vol. 270, pp. 49-56, 2018.

[42] Y. S. Hamirani, S. Pandey, J. J. Rivera et al., "Markers of inflammation and coronary artery calcification: A systematic review," Atherosclerosis, vol. 201, no. 1, pp. 1-7, 2008.

[43] R. Pecoits-Filho, B. Lindholm, and P. Stenvinkel, "The malnutrition, inflammation, and atherosclerosis (MIA) syndrome-the heart of the matter," Nephrology Dialysis Transplantation, vol. 17, 11, pp. 28-31, 2002.

[44] J. P. Kooman, M. J. Dekker, L. A. Usvyat et al., "Inflammation and premature aging in advanced chronic kidney disease," American Journal of Physiology-Renal Physiology, vol. 313, no. 4, pp. F938-F950, 2017.

[45] L. Dai, E. Golembiewska, B. Lindholm, and P. Stenvinkel, "EndStage Renal Disease, Inflammation and Cardiovascular Outcomes," Contributions to Nephrology, vol. 191, pp. 32-43, 2017.

[46] V. Campean, D. Neureiter, B. Nonnast-Daniel, C. Garlichs, M.L. Gross, and K. Amann, "CD40-CD154 expression in calcified and non-calcified coronary lesions of patients with chronic renal failure," Atherosclerosis, vol. 190, no. 1, pp. 156-166, 2007.

[47] K. Benz, I. Varga, D. Neureiter et al., "Vascular inflammation and media calcification are already present in early stages of chronic kidney disease," Cardiovascular Pathology, vol. 27, pp. 57-67, 2017.

[48] D. L. Wachter, D. Neureiter, V. Campean, K. Hilgers et al., "Insitu analysis of mast cells and dendritic cells in coronary atherosclerosis in chronic kidney disease (CKD)," Histology and Histopathology, 2018.

[49] J. Swedenborg, M. I. Mäyränpää, and P. T. Kovanen, "Mast cells: Important players in the orchestrated pathogenesis of abdominal aortic aneurysms," Arteriosclerosis, Thrombosis, and Vascular Biology, vol. 31, no. 4, pp. 734-740, 2011.

[50] Y. V. Bobryshev, R. S. A. Lord, S. Rainer, O. S. Jamal, and V. F. Munro, "Vascular dendritic cells and atherosclerosis," Pathology - Research and Practice, vol. 192, no. 5, pp. 462-467, 1996.

[51] Y. V. Bobryshev and R. S. A. Lord, "Langhans cells of human arterial intima: Uniform by stellate appearance but different by nature," Tissue \& Cell, vol. 28, no. 2, pp. 177-194, 1996.

[52] Y. V. Bobryshev and R. S. A. Lord, "Detection of vascular dendritic cells accumulating calcified deposits in their cytoplasm," Tissue \& Cell, vol. 30, no. 3, pp. 383-388, 1998.

[53] Y. V. Bobryshev and R. S. A. Lord, "Mapping of vascular dendritic cells in atherosclerotic arteries suggests their involvement in local immune-inflammatory reaction," Cardiovascular Research, vol. 37, no. 3, pp. 799-810, 1998.

[54] Y. V. Bobryshev, "Dendritic cells and their role in atherogenesis," Laboratory Investigation, vol. 90, no. 7, pp. 970-984, 2010.

[55] K. E. Paulson, S.-N. Zhu, M. Chen, S. Nurmohamed, J. JongstraBilen, and M. I. Cybulsky, "Resident intimal dendritic cells accumulate lipid and contribute to the initiation of atherosclerosis," Circulation Research, vol. 106, no. 2, pp. 383-390, 2010.

[56] I. Bot and E. A. L. Biessen, "Mast cells in atherosclerosis," Thrombosis and Haemostasis, vol. 106, no. 5, pp. 820-826, 2011.

[57] T. Eleftheriadis, G. Antoniadi, V. Liakopoulos, C. Kartsios, and I. Stefanidis, "Disturbances of acquired immunity in hemodialysis patients," Seminars in Dialysis, vol. 20, no. 5, pp. 440-451, 2007. 
[58] M. Girndt, M. Sester, U. Sester, H. Kaul, and H. Köhler, "Molecular aspects of T- and B-cell function in uremia," Kidney International Supplements, vol. 59, no. 78, pp. S206-S211, 2001.

[59] W. H. Lim, S. Kireta, E. Leedham, G. R. Russ, and P. T. Coates, "Uremia impairs monocyte and monocyte-derived dendritic cell function in hemodialysis patients," Kidney International, vol. 72, no. 9, pp. 1138-1148, 2007.

[60] M. Hueso, J. Torras, M. Carrera, A. Vidal, E. Navarro, and J. Grinyó, "Chronic Kidney Disease is associated with an increase of Intimal Dendritic cells in a comparative autopsy study," Journal of Inflammation, vol. 12, p. 26, 2015.

[61] E. A. Van Vré, H. Bult, V. Y. Hoymans, V. F. I. Van Tendeloo, C. J. Vrints, and J. M. Bosmans, "Human C-reactive protein activates monocyte-derived dendritic cells and induces dendritic cellmediated T-cell activation," Arteriosclerosis, Thrombosis, and Vascular Biology, vol. 28, no. 3, pp. 511-518, 2008.

[62] I. Bot, M. Bot, S. H. Van Heiningen et al., "Mast cell chymase inhibition reduces atherosclerotic plaque progression and improves plaque stability in ApoE-/- mice," Cardiovascular Research, vol. 89, no. 1, pp. 244-252, 2011.

[63] Y. V. Bobryshev, "Targeting vascular calcification: Up-date," Current Pharmaceutical Design, vol. 20, no. 37, pp. 5799-5800, 2014.

[64] B. F. Sena, J. L. Figueiredo, and E. Aikawa, "Cathepsin S As an Inhibitor of Cardiovascular Inflammation and Calcification in Chronic Kidney Disease," Frontiers in Cardiovascular Medicine, vol. 4 , p. 88, 2018. 


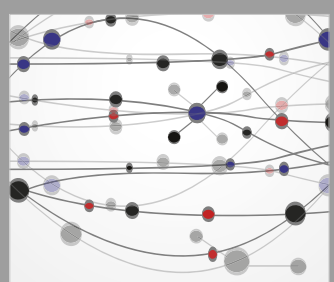

The Scientific World Journal
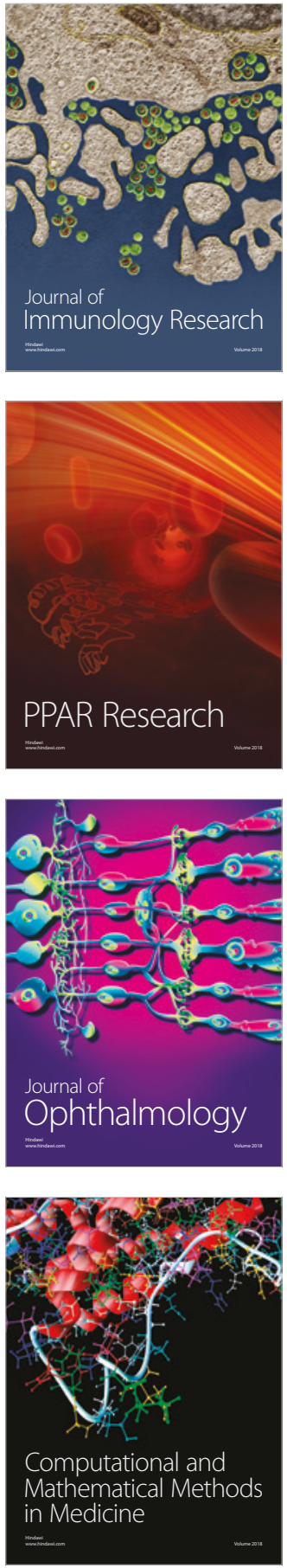

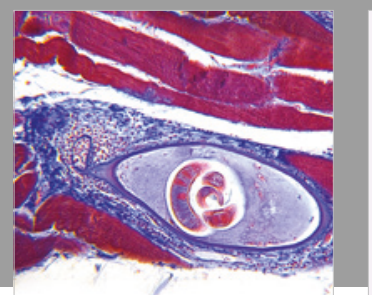

Gastroenterology Research and Practice

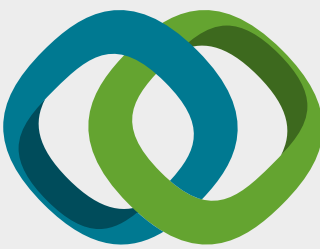

\section{Hindawi}

Submit your manuscripts at

www.hindawi.com
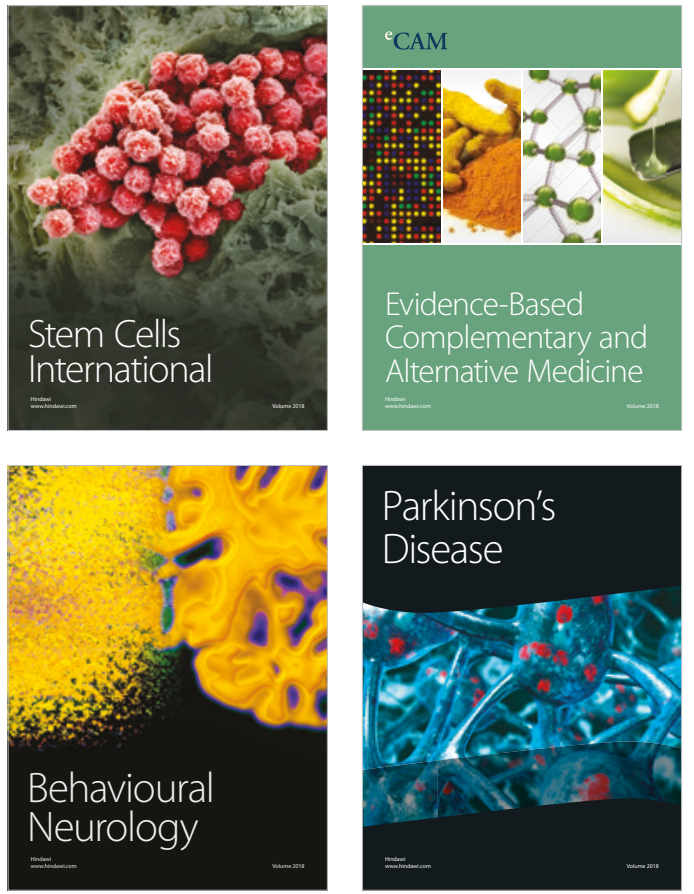

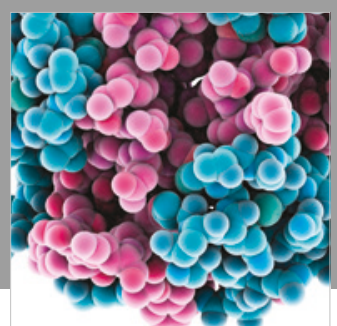

ournal of

Diabetes Research

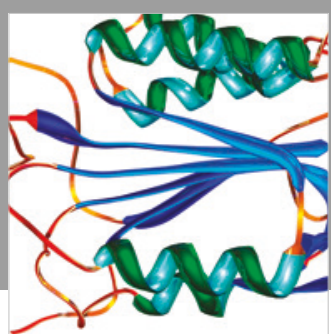

Disease Markers
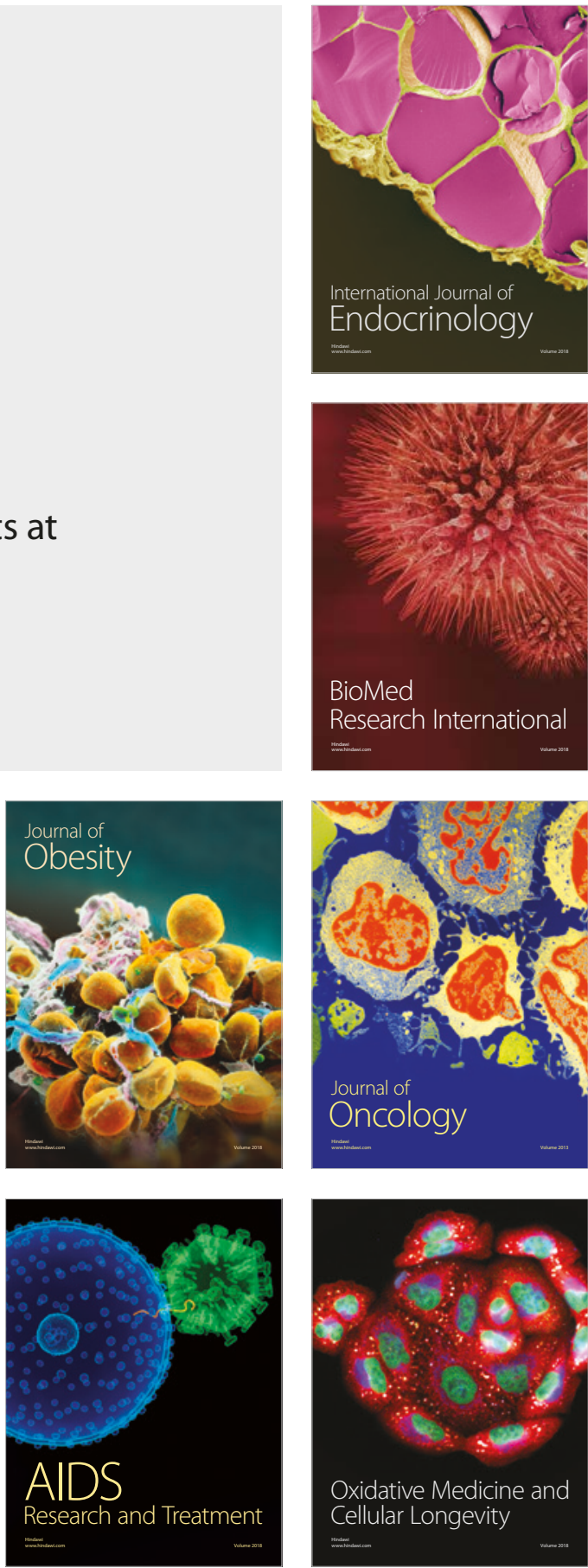